\title{
Plasma creatine kinase and all-cause mortality in patients on peritoneal dialysis: a multi-center retrospective study
}

\section{Yueqiang Wen}

Guangzhou Medical University

\section{FenFen Peng}

Zhujiang Hospital

\section{Xiaoran Feng}

Nanchang University

Niansong Wang

Shanghai Jiao Tong University

Xiaojiang Zhan

Nanchang University

Xianfeng Wu (D xianfengwu2019@gmail.com)

Shanghai Jiao Tong University

Research article

Keywords: Creatine kinase, Mortality, Peritoneal dialysis

Posted Date: January 11th, 2020

DOI: https://doi.org/10.21203/rs.2.20630/v1

License: (1) This work is licensed under a Creative Commons Attribution 4.0 International License. Read Full License 


\section{Abstract}

\section{Background}

Higher plasma creatine kinase (CK) values are associated with the failure of antihypertensive treatment. However, an association between CK and all-cause mortality in peritoneal dialysis (PD) patients has received little attention.

\section{Methods}

In this retrospective multicenter study, 1382 incident PD patients with baseline CK values were enrolled from November 1, 2005, to February 28, 2017. All patients with oral statins were excluded and then were divided into four groups according to quartile range [Quartile 1 (<60 U/L), Quartile 2 (60-100 U/L), Quartile 3 (101-179 U/L), and Quartile 4 (>179 U/L)]. The primary endpoint was all-cause mortality. The association between plasma CK values and all-cause mortality was assessed with Cox regression and the Fine and Gray models.

\section{Results}

Of 1382 patients 298 (21.6\%) patients died during a median 35-month (interquartile range=19-54 months) follow-up period. Patients in Quartile 4 were older $(P<0.001)$, likely to be male $(P<0.001)$, had a higher prevalence of diabetes $(P=0.002)$, and a history of cardiovascular disease $(P=0.005)$, and higher values of Charlson comorbidity index $(\mathrm{P}=0.031)$. All-cause mortality incidence was a significant difference among the four Quartiles (Quartile 1, 16.2\%; Quartile 2, 22.2\%; Quartile 3, 23.8\%; Quartile 4, $24.1 \% ; P=0.043)$. Cumulative all-cause mortality in the Quartile 4 was significantly higher compared with other groups (Log Rank=10.55, $\mathrm{P}=0.015$ ). After adjusting for confounding factors, the highest CK quartile had a hazard ratio (HR) for all-cause mortality of 1.75 [95\% confidence interval $(\mathrm{Cl}) 1.34-3.20, \mathrm{P}=0.041]$. With kidney transplantation or hemodialysis as a competing risk, the Quartile 4 had an HR for all-cause mortality of $1.66(95 \% \mathrm{Cl} 1.30-3.41, \mathrm{P}=0.044)$, after adjusting for confounding factors.

\section{Conclusions}

Higher plasma CK levels at the commencement of PD may be a valuable biomarker for predicting the development of all-cause mortality in PD patients.

\section{Background}

High creatine kinase (CK) is associated with the failure of antihypertensive treatment and is an important predictor of blood pressure and the failure of antihypertensive drugs in the general population [1]. Previous studies have shown that high CK activity promotes hypertension by enhancing vasoconstriction and renal sodium retention [2]. Subsequently, in a randomized sample of a multiethnic population in Amsterdam, the Netherlands, CK was a significant independent predictor of blood pressure levels and the failure of antihypertensive treatment. Subjects with the highest levels of CK activity were male, obese, and 
West African. The crude blood pressure (BP) increase per log CK increase was substantial at $14 \mathrm{mmHg}$ for systolic BP and nine $\mathrm{mmHg}$ for diastolic BP $[3,4]$.

On the other hand, plasma CK is associated with decreased inflammation in obesity, whereas higher inflammation is associated with higher obesity-related cardiovascular disease (CVD) [5-7]. Besides, CK and lean body mass were inversely and independently associated with C-reactive protein in 454 overweight and obese individuals, supporting the anti-inflammatory effects of plasma CK [8]. Thus, plasma CK may have beneficial and detrimental effects on prognosis in the general population.

Among peritoneal dialysis (PD) patients, chronic inflammation is a well-recognized nontraditional risk factor that contributes to excessive mortality [9]. Therefore, plasma CK supporting the anti-inflammatory effects may also have beneficial effects on the prognosis of PD patients. However, on the other hand, high plasma CK levels promote hypertension through enhanced vascular contractility and renal sodium retention [2]. These findings suggested that plasma CK may also have beneficial and detrimental effects on clinical outcomes in PD patients. Therefore, it was difficult to speculate on the association between CK levels and mortality in PD patients. The aim of this study was to evaluate the association between plasma CK levels and mortality in PD patients.

\section{Methods}

\section{Study Population and Data Collection}

This was a multicenter retrospective cohort study. Incident PD patients with PD as their first renal replacement treatment modality were enrolled from four PD centers from November 1, 2005, to February 28 , 2017. Patients lacking plasma CK at baseline, younger than 18 years, or on PD for less than three months were excluded from this study. We excluded PD patients who were using statins because these drugs may cause an increase in plasma CK activity. The study was consistent with the ethical principles of the Declaration of Helsinki and was approved by the Human Ethics Committee of each research center. Written informed consent was obtained from all participants.

Baseline demographic data included age, sex, diabetes, a history of CVD, hypertension, Charlson comorbidity index $(\mathrm{CCl})$, and medication use [including calcium channel blockers (CCB), angiotensinconverting enzyme inhibitors/angiotensin receptor blockers (ACEI/ARB), diuretics and $\beta$-blockers]. Clinical and biochemical data at the initiation of PD included body mass index (BMI), BP, hemoglobin, albumin, total cholesterol, triglycerides, aspartate aminotransferase (AST), alanine transaminase (ALT), serum uric acid, high-sensitivity C-reactive protein (hs-CRP), serum sodium, calcium, phosphorus, and 24-hr urine output. The CK values at the initiation of PD were also collected under resting conditions. CVD was defined as coronary events, arrhythmias, congestive heart failure, cerebrovascular events, or peripheral vascular disease [10]. As one of the most commonly used comorbidity models, the comorbidity score was determined based on the $\mathrm{CCl}[11]$. 
The primary endpoint was all-cause mortality, which was determined by the PD follow-up panels composed of PD primary nurses and professors. If death had two or more potential causes, we generally ascribed the death to the primary cause for hospitalization or the initial presenting condition. If a patient died within three months of transfer to hemodialysis therapy, he or she was not censored because the early mortality was considered to reflect health status during the period of failing PD treatment. All patients were followed up until the cessation of PD, death, or May 31, 2017. The censored data included switching to HD, kidney transplantation, moving to another center, loss to follow-up, or still at four PD centers with a follow-up duration of 8 years. All patients received continuous ambulatory PD treatment. Conventional PD solutions (Dianeal 1.5\%, 2.5\%, or 4.25\% dextrose; Baxter Healthcare, Guangzhou, China), $Y$ sets, and twin bag systems were used in all PD patients.

\section{Statistical Analyses}

Patients with measured plasma CK values were classified into quartiles: Quartile $1<60 \mathrm{U} / \mathrm{L}$, Quartile $2=$ 60-100 U/L, Quartile 3 = 101-179 U/L, and Quartile $4>179 \mathrm{U} / \mathrm{L}$. Participant characteristics were calculated by the Quartiles of plasma CK. The results are expressed as the frequency and percentage of the categorical variables, the mean and standard deviation of the continuous variables of the normal distribution, and the median and quartile range of the continuous variables of the non-normal distribution. Chi-squared test, one-way ANOVA, or Kruskal-Wallis test were used to test for differences in classification factors among different categories of plasma CK. The correlations between plasma CK levels and baseline parameters were assessed by correlation analysis. Survival times were estimated from Kaplan-Meier curves, and differences in survival probability among groups were assessed using a Log Rank test. The association between plasma CK Quartiles and all-cause mortality was evaluated by the Cox regression model. Unadjusted associations (model 1) were first examined, followed by adjustments for age, sex, $\mathrm{CCl}$, and the use of medication (model 2). Next, systolic and diastolic BP, hemoglobin, albumin, sodium, calcium, phosphorus, and 24-hour urine output were added into model 2 (model 3).

\section{Sensitivity Analyses}

The Fine and Gray competing risk model was performed with the covariates included in the Cox regression model, and kidney transplantation or transfer to hemodialysis was considered as the competing event.

The results of the Cox analysis and the Fine and Gray method were presented as the hazard ratio (HR) and the $95 \%$ confidence interval $(95 \% \mathrm{Cl})$. Statistical analyses were performed using GraphPad software 8.0 (GraphPad Prism Software Inc., San Diego, California) and the R package (https://www.r-project.org/). A value of $P<0.05$ was considered statistically significant.

\section{Results}

\section{Baseline Patient Characteristics}


A total of 2224 incident PD patients were enrolled, of whom ten patients were younger than 18 years, 84 patients were on PD less than three months, 196 patients were using statins, and 552 patients lacked plasma CK levels at baseline were excluded. The remaining 1382 patients had plasma CK levels measured at baseline and were eligible for the present analysis (Fig. 1). The mean age was $51.1 \pm 14.8$ years, $56.9 \%$ of patients were male, $23.4 \%$ of patients had diabetic, $16.4 \%$ of patients had a history of CVD, and $71.9 \%$ of patients had hypertension. The mean CCI was $4.53 \pm 1.46$, CCB use was prescribed for $72.9 \%$ of patients, ACEI/ARB use was prescribed for $31.6 \%$ of patients, diuretic use was prescribed for $8.2 \%$ of patients, and $\beta$-blocker use was prescribed for $31.9 \%$ of patients.

Baseline plasma CK levels ranged from 8 to $13585 \mathrm{U} / \mathrm{L}$ (median $=100 \mathrm{U} / \mathrm{L}$, interquartile range $=60-$ $179 \mathrm{U} / \mathrm{L}$ ). The baseline characteristics of the patients by Quartiles of plasma CK levels are shown in Table 1. Patients in Quartile 4 were older $(P<0.001)$, likely to be male $(P<0.001)$, had a higher prevalence of diabetes $(P=0.002)$, and a history of cardiovascular disease $(P=0.005)$, and higher values of $C C l(P=$ 0.031 ). 
Table 1

Baseline characteristics stratified by quartiles of baseline plasma CK levels

\begin{tabular}{|c|c|c|c|c|c|}
\hline Variables & $\begin{array}{l}\text { Quartile } 1 \text { ( } n= \\
341)\end{array}$ & $\begin{array}{l}\text { Quartile } 2 \text { ( } n= \\
345)\end{array}$ & $\begin{array}{l}\text { Quartile } 3 \text { ( } n= \\
349)\end{array}$ & $\begin{array}{l}\text { Quartile } 4 \text { ( } n= \\
347)\end{array}$ & $\begin{array}{l}P \\
\text { value }\end{array}$ \\
\hline Age (years) & $49.4 \pm 15.1$ & $50.4 \pm 14.3$ & $50.8 \pm 14.3$ & $54.0 \pm 15.3$ & $\begin{array}{l}<.001 \\
0.001\end{array}$ \\
\hline Male (\%) & $128(37.5)$ & $191(55.4)$ & $219(62.8)$ & $248(71.5)$ & $\begin{array}{l}< \\
0.001\end{array}$ \\
\hline Diabetes (\%) & $74(21.7)$ & $61(17.7)$ & $85(24.4)$ & $103(29.7)$ & 0.002 \\
\hline $\begin{array}{l}\text { A history of CVD } \\
(\%)\end{array}$ & $39(11.5)$ & $60(17.4)$ & $53(15.2)$ & $74(21.4)$ & 0.005 \\
\hline Hypertension (\%) & $274(72.4)$ & $250(72.5)$ & $247(70.8)$ & $250(72.0)$ & 0.955 \\
\hline $\mathrm{CCl}$ & $4.51 \pm 1.37$ & $4.37 \pm 1.34$ & $4.56 \pm 1.53$ & $4.69 \pm 1.57$ & 0.031 \\
\hline CCB use (\%) & $231(67.7)$ & $257(74.5)$ & $259(74.2)$ & $260(74.9)$ & 0.109 \\
\hline ACEI/ARB use (\%) & $96(28.2)$ & $112(32.5)$ & $116(33.2)$ & $113(32.6)$ & 0.462 \\
\hline Diuretic use (\%) & $24(7.0)$ & $23(6.7)$ & $36(10.3)$ & $31(8.9)$ & 0.263 \\
\hline$\beta$-Blocker use (\%) & $118(34.6)$ & $116(33.6)$ & $118(33.8)$ & $89(25.6)$ & 0.038 \\
\hline BMI $\left(\mathrm{kg} / \mathrm{m}^{2}\right)$ & $21.8 \pm 3.4$ & $22.2 \pm 3.2$ & $22.1 \pm 3.2$ & $22.6 \pm 3.1$ & 0.013 \\
\hline $\begin{array}{l}\text { Systolic BP } \\
(\mathrm{mmHg})\end{array}$ & $147 \pm 26$ & $149 \pm 26$ & $148 \pm 26$ & $152 \pm 25$ & 0.108 \\
\hline $\begin{array}{l}\text { Diastolic BP } \\
(\mathrm{mmHg})\end{array}$ & $85 \pm 14$ & $87 \pm 15$ & $87 \pm 16$ & $89 \pm 17$ & 0.025 \\
\hline $\begin{array}{l}\text { Hemoglobin } \\
(\mathrm{g} / \mathrm{dl})\end{array}$ & $7.83 \pm 1.66$ & $8.57 \pm 1.79$ & $8.40 \pm 1.72$ & $8.55 \pm 1.83$ & $\begin{array}{l}<.001 \\
0.00\end{array}$ \\
\hline Albumin $(\mathrm{g} / \mathrm{dl})$ & $3.39 \pm 0.55$ & $3.50 \pm 0.52$ & $3.44 \pm 0.55$ & $3.42 \pm 0.54$ & 0.042 \\
\hline $\begin{array}{l}\text { Cholesterol } \\
(\mathrm{mg} / \mathrm{dl})\end{array}$ & $165 \pm 47$ & $163 \pm 44$ & $166 \pm 44$ & $165 \pm 48$ & 0.801 \\
\hline $\begin{array}{l}\text { Triglycerides } \\
(\mathrm{mg} / \mathrm{dl})\end{array}$ & $104(74-150)$ & $120(83-173)$ & $115(82-155)$ & $133(91-200)$ & $\begin{array}{l}<.001 \\
0.00\end{array}$ \\
\hline $\operatorname{ALT}(\mathrm{u} / \mathrm{l})$ & $10(6-16)$ & $11(7-17)$ & $12(8-18)$ & $16(9-26)$ & $\begin{array}{l}<.001 \\
0.001\end{array}$ \\
\hline
\end{tabular}

$\mathrm{CK}$, creatine kinase; CVD, cardiovascular disease, $\mathrm{CCl}$, Charlson comorbidity index; $\mathrm{CCB}$, calcium channel blocker; ACEI/ARB, angiotensin converting enzyme inhibitor/angiotensin receptor blocker; $\mathrm{BMI}$, body mass index, ALT, alanine transaminase, AST, aspartate aminotransferase; hs-CRP, highsensitivity C-reactive protein. 


\begin{tabular}{|c|c|c|c|c|c|}
\hline Variables & $\begin{array}{l}\text { Quartile } 1 \text { ( } n= \\
341 \text { ) }\end{array}$ & $\begin{array}{l}\text { Quartile } 2 \text { ( } n= \\
345)\end{array}$ & $\begin{array}{l}\text { Quartile } 3 \text { (n = } \\
\text { 349) }\end{array}$ & $\begin{array}{l}\text { Quartile } 4 \text { (n = } \\
347)\end{array}$ & $\begin{array}{l}P \\
\text { value }\end{array}$ \\
\hline AST (u/l) & $16(12-22)$ & $16(13-22)$ & $17(13-22)$ & $20(16-27)$ & $\dot{0.001}$ \\
\hline Uric acid (mg/dl) & $7.19 \pm 2.24$ & $7.57 \pm 2.24$ & $7.65 \pm 2.02$ & $7.38 \pm 2.03$ & 0.052 \\
\hline hs-CRP (mg/dl) & $\begin{array}{l}20.5(8.8- \\
36.7)\end{array}$ & $\begin{array}{l}21.5(5.2- \\
39.6)\end{array}$ & $\begin{array}{l}18.8(5.9- \\
37.9)\end{array}$ & $\begin{array}{l}23.8(8.9- \\
50.8)\end{array}$ & 0.154 \\
\hline Sodium $(\mathrm{mg} / \mathrm{dl})$ & $319.0 \pm 10.2$ & $320.9 \pm 8.9$ & $321.5 \pm 8.3$ & $323.3 \pm 7.4$ & $\dot{0.001}$ \\
\hline Calcium (mg/dl) & $8.22 \pm 0.84$ & $8.10 \pm 0.92$ & $7.94 \pm 0.92$ & $7.33 \pm 1.04$ & $\stackrel{<}{0.001}$ \\
\hline $\begin{array}{l}\text { Phosphorus } \\
\text { (mg/dl) }\end{array}$ & $6.81 \pm 2.08$ & $7.21 \pm 2.44$ & $7.49 \pm 2.36$ & $7.74 \pm 2.24$ & $\dot{0} 001$ \\
\hline $\begin{array}{l}\text { 24-hr urine output } \\
\text { (ml) }\end{array}$ & $\begin{array}{l}900(500- \\
1200)\end{array}$ & $\begin{array}{l}800(465- \\
1200)\end{array}$ & $\begin{array}{l}700(350- \\
1100)\end{array}$ & $\begin{array}{l}700(500- \\
1100)\end{array}$ & 0.001 \\
\hline \multicolumn{6}{|c|}{$\begin{array}{l}\text { CK, creatine kinase; } C V D \text {, cardiovascular disease, } \mathrm{CCl} \text {, Charlson comorbidity index; } \mathrm{CCB} \text {, calcium } \\
\text { channel blocker; ACEI/ARB, angiotensin converting enzyme inhibitor/angiotensin receptor blocker; } \\
\text { BMI, body mass index, ALT, alanine transaminase, AST, aspartate aminotransferase; hs-CRP, high- } \\
\text { sensitivity C-reactive protein. }\end{array}$} \\
\hline
\end{tabular}

Correlation analyses indicated that plasma CK levels were positively correlated with age $(P=0.001)$, systolic BP $(P=0.027)$, diastolic BP $(P=0.033)$, sodium $(P=0.002)$ and phosphorus levels $(P=0.001)$ and were negatively correlated with calcium levels $(P=0.025)$.

\section{Quartiles of CK and All-Cause Mortality}

The median follow-up period was 35 months (interquartile range $=19-54$ months). By the end of this study, 298 (21.6\%) patients had died, 70 (5.1\%) patients had received kidney transplantation, 193 (14.0\%) patients had transferred to hemodialysis, $7(0.5 \%)$ patients had transferred to other PD centers, and 32 (2.3\%) patients had been lost to follow-up. The remaining $782(56.6 \%)$ patients were still followed at these PD centers. Of the 298 deaths, 196 (65.8\%) deaths were caused by CVD, 54 (18.1\%) deaths were caused by infectious disease, $49(16.4 \%)$ deaths were caused by other reasons, and $45(15.1 \%)$ deaths were caused by an unknown reason. There were significantly differences on all-cause mortality in these groups (Quartile 1, 16.2\%; Quartile 2, 22.2\%; Quartile 3, 23.8; Quartile 4, 24.1\%; P = 0.043). Subgroup analyses found that similar trends were observed in males and those without diabetic subgroups $(\mathrm{P}=$ 0.038 and $P=0.035$ ). At the end of 1,3 and 5 years, the all-cause mortality was $9 \%, 19 \%$ and $27 \%$ in the Quartile 1, 13\%, 22\% and 29\% in the Quartile 2; 15\%, 27\% and 36\% in the Quartile 3; and $16 \%, 29 \%$ and $42 \%$ in the Quartile 4.

Kaplan-Meier estimates of all-cause mortality for patients with different CK Quartiles are shown (Fig. 2). The cumulative all-cause mortality rate in higher CK Quartile was significantly higher than those in lower 
Quartiles (Log Rank $=11.13, P=0.012$ ). Similar results were observed in the male and non-diabetic subgroups (Log Rank = 9.63, P = 0.045; Log Rank = 12.61, P = 0.006). Adjusted HR for all-cause mortality in different Quartiles of CK was shown in Table 2. Quartile 4 was independently associated with all-cause mortality, even after adjusting for demographics, comorbid conditions, and laboratory parameters (Quartile 1 as a reference, $\mathrm{HR}=1.75,95 \% \mathrm{Cl} 1.34-3.20, \mathrm{P}=0.041$ ). Subgroups analyzed showed that the Quartile 4 had an independently higher risk of all-cause mortality in males $(H R=1.45,95 \% \mathrm{Cl} 1.15-2.46, P$ $=0.021)$ and non-diabetes $(\mathrm{HR}=1.64,95 \% \mathrm{Cl} 1.48-2.47, \mathrm{P}=0.017)$, after adjusting for confounding factors.

Table 2

Adjusted hazards ratio for all-cause mortality in different CK quartiles.

\begin{tabular}{|c|c|c|c|c|c|c|}
\hline \multirow[t]{2}{*}{ Plasma CK } & \multicolumn{2}{|l|}{ Model 1} & \multicolumn{2}{|l|}{ Model 2} & \multicolumn{2}{|l|}{ Model 3} \\
\hline & $\mathrm{HR}(95 \% \mathrm{Cl})$ & $\mathbf{P}$ & $\mathrm{HR}(95 \% \mathrm{Cl})$ & $\mathbf{P}$ & $\mathrm{HR}(95 \% \mathrm{Cl})$ & $\mathbf{P}$ \\
\hline \multicolumn{7}{|c|}{$\begin{array}{l}\text { Cox regression } \\
\text { model }\end{array}$} \\
\hline Quartile 1 & reference & & & & & \\
\hline Quartile 2 & $\begin{array}{l}1.69(1.23- \\
2.84)\end{array}$ & 0.003 & $\begin{array}{l}1.68(1.29- \\
2.96)\end{array}$ & 0.025 & $\begin{array}{l}1.60(1.27- \\
2.95)\end{array}$ & 0.030 \\
\hline Quartile 3 & $\begin{array}{l}1.97(1.24- \\
2.88)\end{array}$ & 0.005 & $\begin{array}{l}1.83(1.18- \\
2.86)\end{array}$ & 0.028 & $\begin{array}{l}1.72(1.16- \\
3.25)\end{array}$ & 0.035 \\
\hline Quartile 4 & $\begin{array}{l}2.17(1.31- \\
2.95)\end{array}$ & 0.023 & $\begin{array}{l}1.96(1.35- \\
2.94)\end{array}$ & 0.031 & $\begin{array}{l}1.75(1.34- \\
3.20)\end{array}$ & 0.041 \\
\hline \multicolumn{7}{|c|}{$\begin{array}{l}\text { Competing risk } \\
\text { model* }^{*}\end{array}$} \\
\hline Quartile 1 & reference & & & & & \\
\hline Quartile 2 & $\begin{array}{l}1.37(1.21- \\
2.86)\end{array}$ & 0.007 & $\begin{array}{l}1.63(1.25- \\
2.99)\end{array}$ & 0.029 & $\begin{array}{l}1.52(1.20- \\
3.15)\end{array}$ & 0.033 \\
\hline Quartile 3 & $\begin{array}{l}1.93(1.20- \\
2.93)\end{array}$ & 0.015 & $\begin{array}{l}1.79(1.15- \\
2.96)\end{array}$ & 0.031 & $\begin{array}{l}1.65(1.10- \\
3.31)\end{array}$ & 0.037 \\
\hline Quartile 4 & $\begin{array}{l}2.11(1.30- \\
2.99)\end{array}$ & 0.026 & $\begin{array}{l}1.92(1.31- \\
2.98)\end{array}$ & 0.034 & $\begin{array}{l}1.66(1.30- \\
3.41)\end{array}$ & 0.044 \\
\hline \multicolumn{7}{|c|}{$\begin{array}{l}\text { *kidney transplantation or transfer to hemodialysis as a competing risk. Model 1: unadjusted. Model } \\
\text { 2: adjusted for age, sex, CCl, and use of medication. Model 3: model } 2 \text { adjusted for systolic and } \\
\text { diastolic BP, hemoglobin, albumin, sodium, calcium, phosphorus and 24-hr urine output. }\end{array}$} \\
\hline
\end{tabular}

\section{Sensitivity Analyses}


For the primary outcome and with renal transplantation or hemodialysis as a competing risk event, the Quartile 4 had an HR for all-cause mortality of $1.66(95 \% \mathrm{Cl} 1.30-3.41, \mathrm{P}=0.044$, Table 2$)$ compared to the Quartile 1, after adjusting for confounding factors. Figure 3 showed that using renal transplantation or hemodialysis as a competing risk event, the Quartile 4 had independently higher risk of all-cause mortality in male $(\mathrm{HR}=1.39,95 \% \mathrm{Cl} 1.09-2.51, \mathrm{P}=0.025)$ and non-diabetes $(\mathrm{HR}=1.57,95 \% \mathrm{Cl} 1.45-2.56$, $\mathrm{P}=0.022$ ) group, after adjusting for confounding factors.

\section{Discussion}

In this multicenter retrospective study, we found that even after adjustment for baseline characteristics and laboratory parameters, higher plasma CK levels were incrementally associated with higher risk of allcause mortality in PD patients, especially in those male and non-diabetes PD patients.

Plasma CK tightly binds to ATP-utilizing enzymes, including $\mathrm{Ca}^{2+}$-ATPase, myosin ATPase, and $\mathrm{Na}^{+} / \mathrm{K}^{+}-$ ATPase, to rapidly regenerate ATP from $A D P, \mathrm{H}^{+}$, and phosphocreatine [12]. Usually, the release of $\mathrm{CK}$ from tissues is proportional to the intracellular CK concentration, a physiological process that occurs without tissue damage, as summarized by Brewster [3]. Therefore, the plasma CK of healthy people at rest reflects the tissue CK concentration $[3,4,13]$. However, as lymphatic flow increases with exercise, CK from the interstitial space may enter the circulation rather abruptly and be cleared by the liver in approximately three days [3]. An elevation of plasma CK levels is seen following acute myocardial infarction, rhabdomyolysis, intramuscular injections, and strenuous physical activity. A high tissue CK level is thought to result in a phenotype with greater vasoconstriction and enhanced sodium retention by greater ATP-buffering capacity of ATPases involved in ion transport and contractile responses $[2,3,12,14]$.

Previous studies found that relatively high CK is thought to enhance ATP-demanding processes, including resistance to arterial contractility and sodium retention, and to reduce ADP-dependent function in the general population $[12,15]$. Subsequently, in a randomized sample of a multiethnic population in Amsterdam, the Netherlands, CK proved to be an important independent predictor of blood pressure levels and the failure of antihypertensive treatment [3]. This study found that after adjusting for age, gender, $\mathrm{BMI}$, and ethnicity, CK was independently associated with BP and with systolic and diastolic BP, increasing by 8.0 and $4.7 \mathrm{mmHg} / \log \mathrm{CK}$, respectively. Since then, several other studies have reported that plasma CK levels are associated with the failure of antihypertensive drug treatment $[4,15]$. In addition, plasma CK has been associated with decreased inflammation in obesity, while inflammation is associated with obesity-related CVD [14]. Notably, plasma CK along with lean body mass is inversely and independently associated with hs-CRP in overweight and obese individuals, supporting the antiinflammatory effects of CK. Thus, these findings suggest that CK may also have beneficial and detrimental effects on the prognosis of patients. Therefore, it is difficult to speculate on the association between $\mathrm{CK}$ and death in PD patients. To date, little is known about the association between plasma CK levels and all-cause mortality in PD patients. Our study showed that high plasma CK Quartiles were associated with higher risk of all-cause mortality in PD patients, independent of confounding factors, such as age, sex, $\mathrm{CCl}, \mathrm{CCB}$ use, ACEls/ARBs use, $\beta$-blocker use and diuretic use. Meanwhile, we found that 
the results from the competing risk model were consistent with the Cox regression models. Additionally, similar results were also observed in the male and those without diabetes. These findings suggested that monitoring plasma CK levels may be beneficial for improving the prognosis of PD patients, especially in the male and those without diabetes.

A possible explanation for the described association between total plasma CK levels and mortality was that plasma CK was associated with the failure of antihypertensive therapy, which has been linked to higher mortality [16]. There is increasing evidence that high plasma CK levels are thought to enhance ATP-demanding processes, including resistance to arterial contractility and sodium retention. In our study, higher plasma CK levels were associated with a higher risk of all-cause death. Our results showed that there was a significantly positive relationship between the levels of plasma CK and BP. It is well known that high BP is associated with high all-cause mortality $[16,17]$. Although the lowest Quartile of CK (< $60 \mathrm{U} / \mathrm{L}$ ) was associated with a lower risk of all-cause death, the mean hemoglobin and albumin levels in the Quartile 1 were significantly lower than those in the Quartile 4. It is well known that lower hemoglobin and albumin, as markers of malnutrition, are associated with a higher risk of all-cause mortality [18]. Additionally, lower plasma CK may be considered a marker of malnutrition and relatively low muscle mass, which has been linked to a higher risk of all-cause mortality $[17,19]$. Thus, these findings suggested that the adverse effect of the failure of antihypertensive treatment of higher CK levels on allcause mortality may be stronger than the protective effect of anti-inflammatory of higher CK levels on allcause mortality, which may lead to increased all-cause mortality in the present study. Therefore, mechanisms of the effect of plasma CK on mortality should be investigated in future studies, and the management of plasma CK may improve the clinical prognosis of PD patients.

The strengths of this study are the multicenter nature of the study, a large number of patients, the ability to adjust for significant risk factors for all-cause mortality, and sensitive analysis of competing risk model. There are some limitations in the present study. First, due to the multicenter design of the cohort, there were some variations in the ascertainment and validation of the endpoint. However, it was a multicenter study; therefore, center-specific effects may be excluded. Second, the retrospective nature of the study allows us to establish associations but not causal relationships. As with all retrospective studies, a potential limitation is that the associations may be influenced by confounding by other risk factors. Because of the restriction of sample size, we did not adjust for all factors associated with higher mortality. Therefore, the effect of residual confounding cannot be eliminated completely. Lastly, the changes in variables and treatments overtime during the follow-up were not included.

\section{Conclusions}

In conclusion, we found an independent association between higher plasma CK levels at the commencement of PD and a higher risk of all-cause mortality in PD patients, especially in males and those without diabetes. These findings suggest that monitoring plasma CK levels may be beneficial for improving the prognosis of PD patients, and clinicians could use plasma CK as a valuable biomarker for mortality in PD patients. 


\section{List Of Abbreviations}

CK, creatine kinase; CVD, cardiovascular disease, $\mathrm{CCl}$, Charlson comorbidity index; $\mathrm{CCB}$, calcium channel blocker; ACEI/ARB, angiotensin converting enzyme inhibitor/angiotensin receptor blocker; BMI, body mass index, ALT, alanine transaminase, AST, aspartate aminotransferase; hs-CRP, high-sensitivity Creactive protein.

\section{Declarations}

Ethics approval and consent to participate: The study was consistent with the ethical principles of the Declaration of Helsinki and was approved by the Human Ethics Committee of the Second Affiliated Hospital of Guangzhou Medical University, Zhujiang Hospital of Southern Medical University, Jiujiang No. 1 People's Hospital, Affiliated Sixth People's Hospital, Shanghai Jiao Tong University, and the First Affiliated Hospital of Nanchang University. Written informed consent was obtained from all participants.

Consent for Publication: All authors have approved the submitted version. All authors have agreed both to be personally accountable for the author's own contributions and to ensure that questions related to the accuracy or integrity of any part of the work, even ones in which the author was not personally involved, are appropriately investigated, resolved, and the resolution documented in the literature.

Availability of data and material: Not applicable.

Competing interests: The authors declare that they have no competing interests.

Funding: No.

Authors' contributions: Yueqiang Wen, contributions to the conception, interpretation of data, and drafted the work; FenFen Peng, the acquisition, analysis and interpretation of data; Xiaoran Feng, the acquisition, analysis and interpretation of data; Niansong Wang, contributions to the conception and design of the work; Xiaojiang Zhan, contributions to the conception and design of the work; Xianfeng Wu, contributions to the conception, design of the work, and revised it.

Acknowledgements: We express our gratitude to all patients who participated in the study.

\section{References}

1. Brewster LM, Karamat FA, van Montfrans GA: Creatine Kinase and Blood Pressure: A Systematic Review. Med Sci (Basel) 2019, 7(4).

2. Brewster LM, Clark JF, van Montfrans GA: Is greater tissue activity of creatine kinase the genetic factor increasing hypertension risk in black people of sub-Saharan African descent? J Hypertens 2000, 18(11):1537-1544. 
3. Brewster LM, Mairuhu G, Bindraban NR, Koopmans RP, Clark JF, van Montfrans GA: Creatine kinase activity is associated with blood pressure. Circulation 2006, 114(19):2034-2039.

4. Oudman I, Kewalbansingh PV, van Valkengoed I, Zwinderman AH, Clark JF, van Montfrans GA, Brewster LM: Creatine kinase is associated with failure of hypertension treatment. J Hypertens 2013, 31(5):1025-1031.

5. Ding D, Wang M, Su D, Hong C, Li X, Yang Y, Zhang Y, Hu G, Ling W: Body Mass Index, High-Sensitivity C-Reactive Protein and Mortality in Chinese with Coronary Artery Disease. PLoS One 2015, 10(8):e0135713.

6. Dutra MT, Avelar BP, Souza VC, Bottaro M, Oliveira RJ, Nobrega OT, Moreno Lima R: Relationship between sarcopenic obesity-related phenotypes and inflammatory markers in postmenopausal women. Clin Physiol Funct Imaging 2017, 37(2):205-210.

7. Tajra V, Tibana RA, Vieira DC, de Farias DL, Teixeira TG, Funghetto SS, Silva AO, de Sousa NM, Willardson J, Karnikowski MG et al: Identification of high responders for interleukin-6 and creatine kinase following acute eccentric resistance exercise in elderly obese women. J Sci Med Sport 2014, 17(6):662-666.

8. Bekkelund $\mathrm{SI}$, Jorde R: Lean body mass and creatine kinase are associated with reduced inflammation in obesity. Eur J Clin Invest 2017, 47(11):803-811.

9. Li PK, Ng JK, Mclntyre CW: Inflammation and Peritoneal Dialysis. Semin Nephrol 2017, 37(1):54-65.

10. Bahrami H, Bluemke DA, Kronmal R, Bertoni AG, Lloyd-Jones DM, Shahar E, Szklo M, Lima JA: Novel metabolic risk factors for incident heart failure and their relationship with obesity: the MESA (MultiEthnic Study of Atherosclerosis) study. J Am Coll Cardio/ 2008, 51(18):1775-1783.

11. Charlson ME, Pompei P, Ales KL, MacKenzie CR: A new method of classifying prognostic comorbidity in longitudinal studies: development and validation. J Chronic Dis 1987, 40(5):373-383.

12. Brewster LM: Creatine kinase, energy reserve, and hypertension: from bench to bedside. Ann Trans/ Med 2018, 6(15):292.

13. Brewster LM, Coronel CM, Sluiter W, Clark JF, van Montfrans GA: Ethnic differences in tissue creatine kinase activity: an observational study. PLoS One 2012, 7(3):e32471.

14. Taherzadeh Z, Karamat FA, Ankum WM, Clark JF, van Montfrans GA, van Bavel E, Brewster LM: The Effect of Creatine Kinase Inhibition on Contractile Properties of Human Resistance Arteries. Am J Hypertens 2016, 29(2):170-177.

15. Johnsen SH, Lilleng H, Wilsgaard T, Bekkelund SI: Creatine kinase activity and blood pressure in a normal population: the Tromso study. J Hypertens 2011, 29(1):36-42.

16. Arnett DK, Blumenthal RS, Albert MA, Buroker AB, Goldberger ZD, Hahn EJ, Himmelfarb CD, Khera A, Lloyd-Jones D, McEvoy JW et al: 2019 ACC/AHA Guideline on the Primary Prevention of Cardiovascular Disease: A Report of the American College of Cardiology/American Heart Association Task Force on Clinical Practice Guidelines. Circulation 2019, 140(11):e596-e646.

17. Kaczmarski KR, Sozio SM, Chen J, Sang Y, Shafi T: Resistant hypertension and cardiovascular disease mortality in the US: results from the National Health and Nutrition Examination Survey 
(NHANES). BMC Nephrol 2019, 20(1):138.

18. Lopez-Gomez JJ, Delgado-Garcia E, Coto-Garcia C, Torres-Torres B, Gomez-Hoyos E, Serrano-Valles C, Castro-Lozano A, Arenillas-Lara JF, de Luis-Roman DA: Influence of Hyperglycemia Associated with Enteral Nutrition on Mortality in Patients with Stroke. Nutrients 2019, 11(5).

19. Nakayama A, Canales C, Yeh DD, Belcher D, McCarthy CM, Quraishi SA: Patient- and Nutrition-Derived Outcome Risk Assessment Score as a Predictor of Mortality in Critically III Surgical Patients: A Retrospective, Single-Center Observational Study. Nutr Clin Pract 2019, 34(3):400-405.

\section{Figures}

PD patients from multi-centers (2005.11.01-2017.02.28)

$$
\mathrm{n}=2224
$$

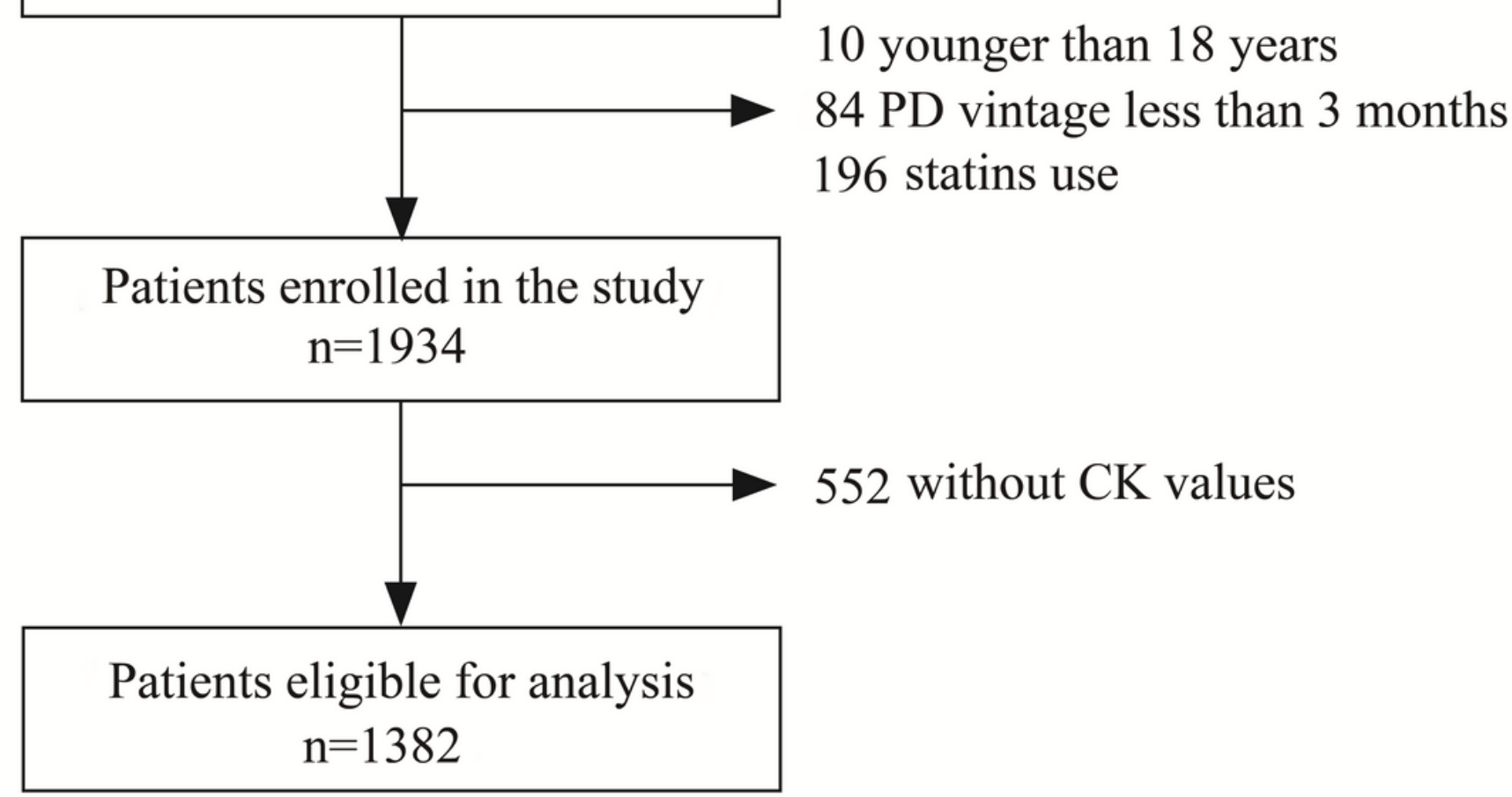

Figure 1

The flow chart showed how patients were selected for the present study. CK, creatine kinase. 
Quartile 4 vs. Quartile 1 (as a reference)

Cox regression model

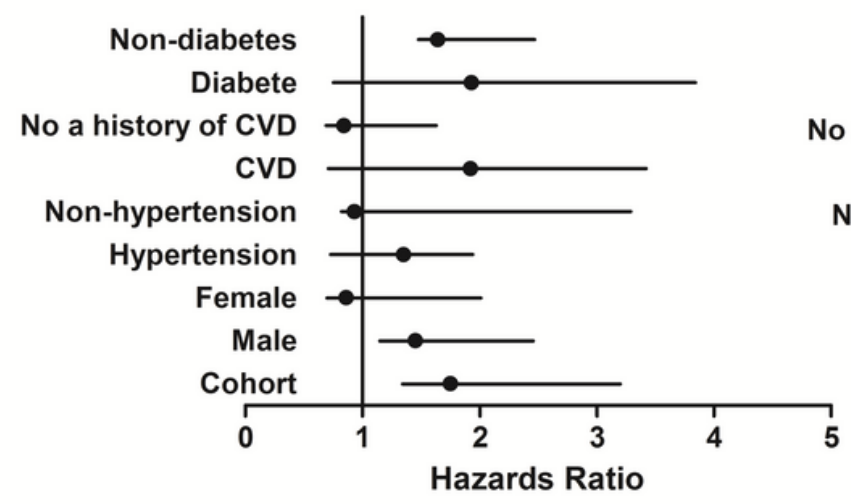

Fine and Gray model

(kidney transplantation or hemodialysis as a competing risk)

\section{Figure 2}

Cumulative all-cause mortality incidence for patients with different CK Quartiles. CK, creatine kinase.
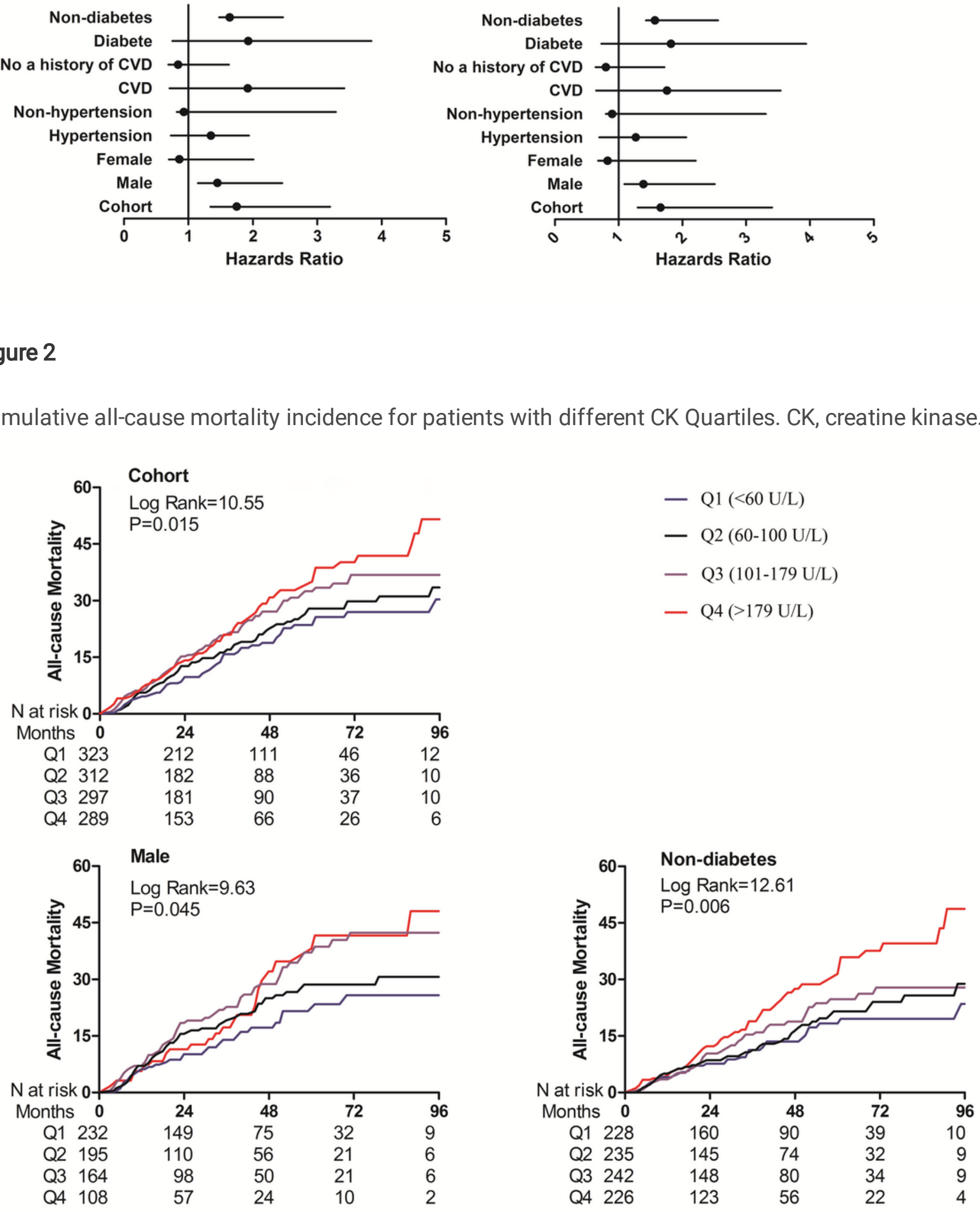


\section{Figure 3}

Adjusted hazards ratio for all-cause mortality. Hazard ratios for Quartile 4 relative to Quartile 1 (adjusted in multivariable models). CVD, cardiovascular disease. 